\title{
Translating Social Differences in Select IWE (Indian Writing in English): A Bilingual Perspective
}

\author{
Bhawna $^{1 *}$, Dr. Pashupati Jha ${ }^{2}$ \\ ${ }^{I}$ PhD Student, Humanities and Social Sciences Department IIT Roorkee, Uttarakhand \\ ${ }^{2}$ Professor of English, HSS Dept., IIT Roorkee, Uttarakhand
}

*Corresponding Author: Bhawna, PhD Student, Humanities and Social Sciences Department IIT Roorkee, Uttarakhand

\begin{abstract}
This paper sets out to address the assimilation of translation and nation as transnational, results in to idea of transculturation. Translation as an art has been taken different paradigm shift. As for creative writing in English, translation is performative nature of cultural communication. Beginning with some remarks on Mulk Raj Anand's Untouchable (1935) and Khushwant Singh's Train to Pakistan (1956), two novels that examine translation as a core of creative writing, this paper proceeds to analyse how Amitav Ghosh uses language to mediate a sense of cultural translation in his writing. Focusing on Ghosh's Sea of Poppies (2008), is further analysed in terms of transcultural narrative. This strange case of creation has been looked through Bhabha's concept of 'transnational translational'. The key is how translation work in practice rather than theory as each writer has his own regional expressions experimentation with English. Translation is implicit in the processes of cultural transformation and change, is used as a metaphor for Indiannism in this context.
\end{abstract}

Keywords: Nativization of English, Indian English Literature, Translation

\section{INTRODUCTION}

In the way of handling the Indian situation in their own ways in IE, particularly, in creative writing it is for sure that this genre of writing is conceived on the ground of bilingualism. In the case of Indian English creative writing the leading figures (Anand and Singh) to the contemporary one (Ghosh) brings experimentation of different Indian regional languages in their creative works, which provides authenticity to the theme corresponding to its language. The question arises as to how writers become more proficient in the other language and what accomplish the attitude show their creativity in that language. As Iyengar puts it: "Indian writing in English is, but one of the voices, in which, Indian speaks. It is a new voice, no doubt, but it is as much Indian as the others" (196:3). When a work of art is created in bilingual mode, it would have to satisfy certain parameter of intelligibility, acceptability, appropriateness. Intelligibility is not an absolute criterion, but is participant and context dependent. Braj B. Kachru in his paper, "The Indianness in Indian English", explains that "the term intelligibility may be used in a wider sense to imply an Indian bilingual's capacity to use English effectively for Social Control"(1965:394). This genre of literature has foreign readers as well as Indian bilingual readers who have some proficiency in English. For the latter one, things are easy, but for the previous one, footnotes and the other hints are required to know the Indianness of the English language. The Indian expressions in other tongue are defined by the appropriate transformation of Indians into Westerns. The Westernization of Indian sensibility provides a big scope for its bilingual readers. Kachru poses an important question in this context; "One might ask who is to judge the appropriateness and acceptance of such innovations? The actual non-native user or an idealized native speaker? The answer is not easy" (1990:28).Writing in some other language presents a different situation where the native expressions are influenced by the other tongue, which creates the concept of otherness. In creative context, the sense of otherness is expressed through the various strategies of translation. In addition to this, Indian English Literature or Indian and World Literatures, as a major discipline has been taking shape in major academic institutions (JNU, EFLU) of India. Translation, resonating the role of Indiannism by the various regional writers of India has been sought to present in 
a unified structure is critiqued for various essential reasons to sometimes save the endangered language or to criticized the globalized medium of English.

N. Kamala in her paper, "Gateway of India: Representing the Nation in English Translation", has discussed the arguments of many Intellectuals who are continually disseminating their voices on the various regional issues. While taking different instances of regional unconsciousness for the writer of the South region to a North one, she points out the argument of Suman Gupta which is worth mentioning to understand the perspective of Indiannism in this context:

That it seems almost natural that anthologists should try to find an adequate Indian experience in the elected texts, should identified with centrist definitions of Indianness at the expense of local realities, should think of the various literatures in Indian languages as a continuous Indian literature, should think of living and experiencing India as one continuous experience, and providing all this with the sonority of an assumed voice of the nation. $(1996,112)$

While discussing it further she has the opinion she makes a paradoxical remark by figuring out the various regional language writers, but there is no Indian literature in Indian languages. What there may be is "a Bengali literature of India, a Tamil literature of India, a Marathi literature of India, and so on-i.e., indigenous literatures which acknowledge perspectives of the nation-people that are conditional upon their local realities" (111). Gupta does acknowledge the possibility of nationalist literatures in various Indian languages under certain political conditions, and constructed against the grain of local realities. But these are unique and discontinuous moments. Under asymmetrical power relationship Indian literatures have shifted grounds of exchange which leads to dramatic changes in conceptualizations of cultural difference. The changing face of translation in Indian literature to Indian English literature, have been providing the motivation and manner for translation. As Alastair Pennycook suggests in his book Language as a Local Practice (2010), Language as a local practice, from this point of view, is not only repeated social activity involving language, but it also, through its relocalization in space and time, the repetition of difference (43). Transfer serves as an effective strategy of acculturation which draws upon shared cultural presupposition. In studies of language contact, it is expected and accepted that borrowed items undergo change due to acculturation and linguistic assimilation. In addition, linguistic and sociolinguistic studies of code-mixing in communities where IVEs are used have shown that English and the local languages operate in complex syntactic relationships within a single sentence.

The term 'translation' is used here in a metaphoric sense, which covers the other ways of transforming the concept of otherness into Indianness. The metaphoric use of the term 'translation' includes 'transcreation', 'transluciferation', 'translumination', 'transtextualization', even 'poetic reorchestration', and the profoundly significant 'reimagination'. The strategy of translation has motivated the postcolonial literary norms in Indian English creative writing. Bhabha's concept of the 'Third Space' is the defined place for emerging transnational and translational creativity. In the creative writings of postcolonial writers like Rushdie and Ghosh, the norms of translation strategy have been transformed into cultural translation. Along with this, there are several claims, which have been raised on the nativity of English language and their translated identity.

\section{NATIVIZATION OF ENGLISH IN INDIA}

There is a great dispute on the concept of nativity of the language and the mother tongue of one person. Most of the writers claim that Indian language is their native language in which they and their ancestor grew up. However, there are some exceptions. The small group of Indian elite society claims that English is their native language because their ancestors were part of the British Government before independence and, after independence; they have the privilege to continue it. For those creative writers, who claim that English is their first language, it creates a sense of cultural innovation, where their own culture is modified in a Western way. Writers like Jhumpa Lahiri who is born of Bengali parents in London has been translated in Bengali as she has written fiction not only about Indians in America but also some stories about Indians. She admits the fact that her knowledge of Bengali which is her parents' mother tongue is inaccessible to her when she gets translated. For this she makes the claim that whether she is writing as an American or An Indian her creative identity is all due to translation. Like Lahiri , Amitav Ghosh who identifies Bengali as his mother tongue, lives abroad and write about Indians as well as of others has been added in world literature - as the ubiquitous Indian Writers in English. 
There is a difference between mother tongue and native language. There is always a difference between taught mother language and the vernacular mother tongue. The taught mother language is concerned with acquiring techniques of control and vertical movement in an artificially created hierarchical society. English taught as mother language is not the same as English taught as mother tongue in U.K. English acquired as mother tongue by the Americans is different from Australian, Anglo-Indian varieties. There is a difference between geographical and social varieties of English, which causes an impact on the taught mother language.

The opposition of native verses non-native turns to be a serious issue in the context of creative writing. The native variety of English could be acquired in acquisitional, socio- cultural, motivational, and functional contexts. From the first perspective, native variety of English could be acquired on the grounds of first language, second language, and foreign language. It is a part of multilingual setting which is provided by the process of hybridization. The nativization of English is expressed through pronunciation and its vocabulary. A vernacular language is identified in a creative context with which one feels close identity, emotional attachment, and which one uses in intimate context. A vernacular is defined sometimes as mother tongue too. European scholars have generally used this term to refer to all modern South Asian languages in a sense distinguishing it from the Classical and the Western languages. According to this, vernacular is a cover term for Bengali, Tamil, Standard Hindi, and, on the other hand, for Magahi, Maithili, or varieties of Kashmiri. The acculturation of these varieties is so deep that the new questions arise that whether a native model of English is described and possible for such non-native varieties! Indian Englishes as a whole maintains varying degrees of Englishes. Their writings seem to present stylistic variations on account of the transcription of their native vernaculars. The paper examines whether their language for creative expressions are their mother tongue expressions or the learned mother tongue influence in the creative context. When we talk about nativity of the language, it makes a difference between mother tongue and native tongue. Sometime, there is a great dispute between the mother tongue and the native tongue. There are different cases when native tongues have a different purpose than the mother tongue.

Nativization of English in India is discussed not only on the basis of indigenization of its linguistic features but also on the basis of its social and cultural use. The social and cultural identification of English with India is a necessary condition for granting its native status in India. This condition is to be met for English to have legitimacy in India. This does not make Indian speakers of English the native speakers of English, whether they acquired it as a second language, as true of the educated community, or acquired it as the first language, as true of the community of partial European descent through intermarriage. Native speaker status is not granted to them in spite of nativization of English in the country, because these speakers of English are in a small proportion. They share the cultural heritage and political power of the speakers of English in centre. It is even important to distinguish between the terms native language and the mother tongue as the notion of native as opposed to foreign always crops up while discussing the teaching of languages. Mother tongue also needs to be differentiated from L1. By implication, in a multilingual situation such as in India, one's native language is differentiated from the regional language in the case of minority language speakers. Being native in this sense becomes identified with the indigenous language; by further implication, any language that has been transplanted from a foreign country within recent memory and has become an indigenous mother tongue, is considered foreign. Thus, although English is the mother tongue of two million Anglo-Indians, the official language of two of its states and the associate official language of the union, it is still considered a foreign language by many.

\section{Indian English in CREATIVE CONTEXT: A Bilingual APPROACH}

There are writers like Mulk Raj Anand, Khushwant Singh and Amitav Ghosh, who have the creative excellence in the otherness of language. Their own way of thinking recreating in various Indian flavours by default, are always in their writings. Unlike the previous two, who transcribed their mother tongue in to the other one, he dismisses 'Indian languages verses English debate' as meaningless and Passé. He not only read and admired contemporary writers in Bengali such as Mahasweta Devi and Sunil Gangopadhyay, he was on excellent terms with them personally. He is of the view that a writer's business is not to write and problematic value could, in his view, be interrogated as effectively through English as through any other 'Indian' language. As a creative writer he confessed that all he had ever wanted to do was to write and everything else arranged itself around this central and singular focus - language, place, profession, family, travel. He moves away 
from the previous kind of literary chutinification towards a more realistic and personal narrative. If we define the concept of mother tongue we find it perplexing that sometime, speakers could not able to define their native expressions in their mother tongue. Indian English speakers can be classified according to their competence in different modes of English and assigned their place in the cline of bilingualism; Bakha (Untouchable), for example, is shown to be a bilingual with very poor control of English. Further, Indian English speakers can be separated on the basis of region as well as ethnicity, so that one might have a person with a very low competence in English, with high interference from the mother tongue. The cline of Englishes in India ranges from educated Indian English to varieties such as Babu English and Butler English. Having placed Bakha low down in this cline, Anand introduces various kinds of grammatical and lexical deviation. Bakha shows respect to Charat Singh on his sense of kindness 'Huzoor it is all your blessing.'(8)

'Huzoor' indicates the class status of the two characters-'Huzoor' being used in the manner for the upper class by their servants-but it may also indicate a difference between higher caste and lower caste, giving Bakha a low class and caste status. In other words, while 'Huzoor' places Charat Singh in a higher class than Bakha it also diminishes his position, making 'a willing slave' of him. On top of all this, 'Huzoor' is also a term of respect, so it is not surprising that it is the one term in this passage left untranslated-for how could all this have been conveyed in English? The deviaition in English are striking in Bakha's first sentence itself.

Bakha of Untouchable is a microcosm of the Indian culture, a society of petty slaves and other menial work. Its inhabitants are caste-less, but subservient to mainstream Hinduism and it structure of power. When the rebellious Bakha asks his father, can't he choose another way of life, Lakha explains that there is no other way for him. This is the way he has survived in life and this is the only way he knows to survive. It is no defence of what he does or has done, but a resigned approach to a social order that turned him into a 'willing slave'. The haunting tune reminds reader at crucial moments in the story that Bakha is a victim of circumstances, he could have grown into a gentrified untouchable in his homeland but for an act of crime he was forced into. There is an instance when Bakha is talking with his friend Chota. Their friendship like talk consists of different kind of taboos associated with it, are unique features of IE.

'What is the matter with you, brother-in-law?' he asked. 'Nothing,' replied Bakha, 'You were running. I came slowly.' 'You didn't look for us?'

'I was tired. I wanted to sleep. I couldn't sleep very well last night.'

'Because you will be a gentreman and won't put a quilt over you as your father says,'

Joked Chota. He learnt from Rakha all that happened to Bakha at home, all the abuse that their father inflicted upon him, and he used to tease him about it.

'Shut up,' retorted Bakha playfully, 'you are more of a gentreman than I am, and look at this brotherin law to-day; he is wearing a sahib's topee and shorts.' (1935:83)

The point here is that although the passage may read like a transcript of the speech of an Indian with low competence in English (i.e. like some kind of Indian English), it is actually carefully constructed translation. They all are teasing each other by calling them brother in law. This term is sometime used as an abusive term. The use of the term gentreman is actually their way of pronunciation of the word gentleman. Their illiteracy and a way up to look like English men. What Anand has attempted here is to locate the character in terms of region, class and gender through the construction of specific English using the strategies and resources of a translator. As Bhabha, in his book The Location of Culture points out.

The work of the word impedes the question of the transparent assimilation of cross-cultural meanings in a unitary sign of 'human' culture. In-between culture, at the point of its articulation of identity or distinctiveness, comes the question of signification. This is not simply a matter of language; it is the question of culture's representation of difference - manners, words, rituals, customs, time - inscribed without a transcendent subject that knows, outside of a mimetic social memory, and across theouboum - kernel of non-sense. What becomes of cultural identity, the ability to put the right word in the right place at the right time, when it crosses the colonial non-sense? (1994:178) 
When Anand writes, readers get a perception that the dialogues are heard in Hindi or in local vernacular expressions. Anand's characters are shaped by a language which is not only different from English, but also markedly different from Hindi which is the language of Anand's most successful fictitious characters, similarly as the use of Bengali, which is reflected in the novel of Amitav Ghosh. The Englishes that these writers create in are not unintentional, and are not merely or wholly illustrative of varieties of Indian English. As stated earlier, many of their characters would not speak English at all, and people who belong to the particular regions concerned may speak English quite differently. The aim of the author is not to create the specific characteristics of the English spoken in the regions they depict but to create an English that fulfils their transnational-creative aims. Singh's Train to Pakistan is all the same depicting the pathos of partition of the villagers of Mano Majra who are being divided among community between India and Pakistan. The sacrifice of Jugga for his beloved is transcribed from Punjabi into English. Singh's experimentation with language successfully brings the feeling of separation on the real ground of the historical event. When Ghosh writes, his writing is perceived by the Bengali readers as their writing is in Bengali or has Bengali aspiration. The question is clear that many examples of eminent writers, writing in a language other than their mother tongue, are found all over the world. On the basis of creative ability, if writers like them claims English as his mother tongue, going by that criterion it will be difficult to reject his claim and the claims of all creative writers who have opted to write in a language other than their first language. These writings are also perceived in the same way.

Driven by the fact that Indian English Literature has the consistency of nativity, creative writers have done a lot of good works to nativize the English expressions.

Salman Rushdie, in his book Satanic Verses, interprets the Koran in the Western way. The fundamentalists charge it as an act of blasphemy. Rushdie's sin lies in opening up a space of discursive contestation that places the authority of the Koran within a perspective of historical and cultural relativism. The work of Salman Rushdie has developed a place for cultural translation, which interprets the Koran in a Western way. Bhabha, in his book The Location of Culture (1994), points out that Rushdie translates this into the migrant's dream of survival: an initiatory interstices; an empowering condition of hybridity; an emergence that turns 'return' into reinscription or redescription; an iteration that is not belated, but ironic and insurgent (324). He further says: "The newness of cultural translation is akin to what Walter Benjamin describes as the 'foreignness of languages' - that problem of representation native to representation itself. If Paul de Man focused on the 'metonymy' of translation, I want to foreground the 'foreignness' of cultural translation" (325). He connects the relationship between these terms by saying that "Translation is the performative nature of cultural communication. It is language in actu (enunciation, positionality) rather than language in situ (propositionality)" (326). Similarly, appropriateness in creative writing is determined by several factors. The native literary and cultural traditions are very important to define appropriateness of the native expressions in Indian writing in English. The native rhetorical styles are then imposed on an "alien" language, which results in functional and communicative varieties in Indian English, which make it distinct from other Englishes.

Mulk Raj Anand, as a creative writer, has sensitively and mindfully imbued the pathetics of Untouchable with caste consciousness. Moving with a sense of caste to Castelessness the narrative of the story in its undertone points out that "despite being at the centre of our attention, caste continues to elude us in fundamental ways- or at least so it would seem". The conversation on caste, though, finds no articulation in the modern, for its mere existence is viewed as "pre-modern" or even "antimodern". The caste system dictates that society is comprised of four varnas or castes. Brahmins, the priestly caste, are on top, followed by Kshatriya, the rulers and soldiers. Vaishyas, the traders, come in third while Shudras, the menial workers, are last in order. The first three are considered twice-born (dwija), purified by rituals and are entitled to wear the sacred-thread. Shudras or menial workers, on the other hand, are the perennial lower caste, their position is absolute. Those who fall beyond the caste spectrum are even worse because they are not only impure but polluting. While such discriminations are commonplace in Indian society, the dynamics of caste work very differently from religious and linguistic identities. A language can be learnt, a new religion can be embraced, but caste is permanent. Caste is so deep-seated in Indian society that supposedly egalitarian religions such as Islam, Christanity and Sikhism also suffer from it. It claims that only "lower caste" transgressors will pay with their lives while "upper caste" transgressor will have an opportunity to be reclaimed. 
Mulk Raj Anand, among others writers, transcreates native situation into English by using native lexical items, hybridization, new collocations, and contextually marked translations of Punjabi or Hindi-Urdu clauses and sentences. Anand's characters, whether they are in Untouchable or in Coolie, are distinguished from one another by their dialects, style range, and diction in Punjabi. In the native context mother tongue needs to be differentiated from L1 (first language acquisition). Anand shows uniformity of trans-creation in his novels because the characters in the novel do not speak native variety of English. So Anand's characters sound artificial, a little unreal, and almost comic to an Indian. This is the price one pays for using an "alien" language in contexts in which it does not ordinary function. Differing bilingual and multilingual pressures have led people to talk of L1 or the first language.

India is defined as a linguistic area where people of different regions have different native expressions. If one gives up this language one may intellectually be alive but emotionally sterile. The novels chosen for my study are from Indian English Literature or contact literatures. These novels have two faces, that are their own thought-process which comes out in the underlying patterns through the complex thought-process, and the face they acquired by linguistic contact with another language and society. The degree of contact with another language determines the impact of other language on particular literature. Indian English Literature is vibrant with its Indianness. The tempo of Indian life and the rhythm of its culture have been blended with the depth of native experiences in their expressions.

These literatures contain the national identity and linguistic distinctiveness. There are various levels of linguistic distinctiveness. The ambivalence is intriguing. And this is exactly what has been getting lost in translation. One side in the aforementioned perspective is the idea and to know how far these authors have succeeded in attaining this colonial authority is really a matter of perception. But, nevertheless, there is a metonymic gap which signifies the place of in-betweenness. And for that to happen, it is going to require a 'cerative nativization' of its own kind in the IWE, which has been long overdue. Such nativization of thought brings the concept of acculturation. The creativity in these writers are not the formal combination of two or more underlying language designs, but also as a creation of cultural, aesthetic, societal and literary norms. The sense of creativity in their writings contains different contexts of situations. These different contexts of situations refer to different kind of nativization of the thought process. The range of saying and the levels of meaning are distinct, and one has to establish renewal of connection with the context of situation. The reader has also a creative role in interpreting the text. These creative expressions demand identification with the literary sensibility of the bilingual in tune with the ways of saying and the levels of new meaning. The stylistic difference creates the problem of authenticity. These situations create the context-free international varieties. A Punjabi English writer will be different from that of South Indian. The stylistic variation always creates the problem of authenticity. The idea of authenticity is achieved by linguistic realization of the following types.

The use of native similes and metaphors, which linguistically result in collocation deviation-- There is a difference between the writing of Anand, Singh, and Ghosh altogether. The starting phase conceived the writing of Anand, who has nativized the English expressions in his simple way. In Untouchable God is signified as "the purifier of the polluted souls" (137). To consider a fellow human being as polluted is sin in Hinduism. In addition, the name of Gods along with other commodities in the novel is footnoted for the sake of bilingual readers. Singh in his novel depicts the addressee who belongs to higher authority metaphorically; Cherisher of the poor (69), King of pearls (79). The land of Mano Majra is depicted as fool's paradise (78). The narrative acquires metaphor suitable for the Punjabi style of writing as in; "Robbing a fellow villager is like stealing from one's mother" (43). The Indian social satire on caste is imposed by the name of the character Iqbal Singh whose name without surname is understood as a Muslim by the Inspector, but with the surname he is understood as Sikh. But he dissociates himself from caste by saying that "I have no religion' or 'Religion is irrelevant' (175). Khushwant Singh moves one step ahead in his writing compared to Anand, whereas Ghosh's writings exceed both of them by becoming more advanced stage in style and theme. He, like himself, portrays his characters as translators: they assume altered identities in an effort to modify a sign system and represent it for the reader. Anand and Singh have the Punjabi background; so their writings are nativized in Punjabi style. While Ghosh is a Bengali descendent, which is very much 
there in his writing, and it often amazes his Bengali bilingual readers. Like Bakha of Untouchable, one of the characters Kalua of Sea of Poppies has been bestowed with all the quality of an outcaste. Kalua is a far moving character from the untouchables of previous kind. Ghosh's characters are a kind of vernacular cosmopolitans, moving in-between cultural traditions, and revealing hybrid forms of life and art that do not have a prior existence within the discrete world of any single culture or language.

The transfer of rhetorical devices for personalizing speech interaction - Anand says that he decided to consciously introduce translation of Punjabi, Urdu and Hindi words into all writings (Naik1973:163). R.K. Narayan, who had the benefit of Graham Greene's editorial recommendation, still manages to write an Indian English, capable of negotiating the terrain between Tamil, and possibly Kannada, and English. He has to make the choices that translators are forced to consider: what to translate from Tamil, which Tamil words to retain, whether to render them in English with certain styles of speech, etc. Narayan says of his generation of writers that "often the writing seemed... an awkward translation of a vernacular rhetoric, mode or idiom. But occasionally it was brilliant" (Narayan 1979:22). This process of transmutation of English, he says, has served his purpose admirably. Khushwant Singh, another writer who has experienced this need to create a new language, calls this Indian English by the quaint term "Indish" (Singh1986:36). His novel creates the perfect environment of cultural translation by applying the rhetorical devices for personalizing speech interaction. "Morality, Meet Singhji, is a matter of money. Poor people cannot afford to have morals. So they have religion" (TTP49). Ghosh, in his more advanced stage, introduces many tongues in his writing by giving specific emphasis on Bengali.

Various kinds of idioms and proverbs, which are used in the novels of Indian English writers, have a different contextual interpretation. Anand has translated the Punjabi proverbs into English from Indian regional languages. Similarly, Ghosh did the same while depicting his Bengali bilingual character, Neel. Their native rustic characters are never depicted the same way as the natives of the English. The character Bakha (Untouchable), and Kalua (Sea of Poppies), speak good English, who had never had acquaintance with that foreign language. They speak almost like educated ladies and gentlemen without any provincialism, which is hardly acceptable to the readers. If the writers have translated their talk into Somerset or the Yorkshire dialect of English, then it would have disturbed the authentic colonial representation of their narratives.

\subsection{Culturally Dependent Speech Styles}

In Kanthapura, Raja Rao, does not claim to be writing in Indian English. He is not writing in British English either. His attempt in Kanthapura is to create a 'rough' text, one that will underscore the otherness of the language. Likewise, Singh in his novel brings out the rhythm of the Punjabi expressions, the tempo of their speech and the configuration of their world- view in his English novel. His characters in the novel, Train to Pakistan, have transformed the Punjabi conversation style into English; "Of course, Chacha. Whatever you say is right to the sixteen anna of the rupee, agreed Meet Singh, rubbing his belly" (TTP63). Like Singh, Ghosh has Bengali characters, who touches the heart of the reader by their native tongue expressions in its changed script.

\subsection{Syntactic Devices}

In Indian writing in English there is seen syntactic variation from AE/BE. The syntactic variation is found in yes-no questions, tag questions. Verma (1973) observes that speakers in IndE do not use the complex rule-generated tag questions available in English, such as; you have eaten, haven't you? Instead they use a finite set of simple tag questions consisting of Is it?, isn't it?, and No? In Train to Pakistan by Singh there is found the same variation in tag question "you must have slept with many mem-sahibs. Yes? (126)." Similarly in Untouchable a systematic pattern is found "'You didn't abuse or hit back, did you?' he asked (71)". In Sea of Poppies there is Neel Ratan Halder, the Raja of Raskhali, who has a similar tone "We have simkim and lól- sharáb, don't we? (45)".

English as a second language in India has incorporated the social and cultural terms, expressions and norms from the vernacular first languages. According to V.K Gokak: “ By Indianism is generally meant a word, phrase, idiom, expression or point of syntactical usage which is not part of current English or American usage and involves a shade of meaning or usage Indian or is reminiscent of the lexis, idiom, phrase or syntax current in one of the modern Indian languages"(A Brief Note: 25). The 
terms and expressions or common "Indiannism" are often difficult to interpret for the western readers. The instances found in Singh's novel such as, "This is Kalyug - the dark age" (TTP53).

The above mentioned features are the common factors found in the writing of all the creative writers. There is a difference between mother tongue and native language. Indian English itself is a place for third space where writers have opted a place for trans-creation of mother tongue into some other language to present the nativity of the language. Bilingual provides the language contact situation where language mixture is a common phenomenon. Bilingual code repertoire is full with bilingual creativity. Language mixture is an accepted linguistic device for stylistic effect. In terms of linguistic units, mixing entails transfer of the unit code a into code $b$ at intersentential and intrasentential levels and thus developing a new restricted code of linguistic interaction. It seems that a user of such a code functions, at least, in a disystem. The resultant code, then, has formal cohesion and functional expectancy with reference to a context. In such a creative context, there is an absorbing code and an absorbed code. The absorbed code is assimilated in absorbing code. A bilingual can easily identify these codes when they have been accomplished with that. The transferred unit may be morphemes, words, phrases, clauses, sentences, and what are traditionally called idioms. A bilingual in general use two or more than two codes then the question arises what is the function of vernacular in that creative context. A vernacular may be identified as a code within which one feels close identity, emotional attachment and which one uses in intimate context. In terms of a hierarchy of prestige, a code immediately next to the code one is identified as a vernacular. It is an attitudinally loaded concept. Functionally restricted codes are labelled as vernacular. A Hindi speaker consider dialect of Hindi as a vernacular even an English speaker consider Hindi as a vernacular. Nonetheless, In Indian English creative writing trans-creation of the words of Bhojpuri, Bengali, and Hindi altogether termed into vernacular expressions.

\section{CONCLUSiON}

The creative aspects of the bilingual writers and their use of language for creativity have yet to be seriously studied by linguists. The distance between the natively used varieties of English and IE can not be explained only by comparative studies of phonology and grammar. The deviations in Indian English from its native variety of English are outcome of the Indianization of English, which has gradually made IE culture-bound in the socio-cultural setting of India. The phonological and grammatical deviations are only a part of Indianization. Along with this, the creative writers should not be perceived with acquisitional inadequacies in a particular language by looking at their codemixing and code-switching processes. In this context, non-native literatures in English have a huge research gap for further study. It is imperfectly imitative but indigenously distinctive in certain ways. Like people words are mixing to each other and bring a sense of newness. Though, it is all the impression of colonial mind-set but a process of self-indulgence. It is a medium of pan-Indian communication. R.C. Goffin in his writing has stated if the compounding and reduplication of late colonial IE are attributable to 'vernacular prepossession', we might consider them as nativized lexicogrammatical formation, which possess a kind of inward Indianness, despite their outward British lexical grab (1934: 34). Writing about untouchability, Partition, marginal voice in Indian English brings Indian philosophy in its undertone in a European cultural context. Apart from adapting a new style of narration, there is also the issue of cultural attitudes with regard to the representation of these issues. This new literary approach is coming out of great social acceptability. Having been initiated by imitating the British style of narrative, writers like Ghosh has been handling it with great dexteriosity. It is obvious that characters of the novel Untouchable -rural villagers - do not, for the most part, speak or think in English; their voices are not transcribed directly, but translated into English from Hindi, the language of the fictional town Bulashah in which the story is set. Whereas in the novel Train to Pakistan the reader is forced to wonder which the language of the characters of Mano Majra aspires more to be--an aurally authentic recreation of Punjabi or a plausible reworking of IE, directly rendered. If more the former than the latter, we might expect the use of Indian English in these novels, which come from the mouths of an untouchable and rural people, is to mark a radical departure from the IE of Anand and Singh's days, which was a dialect of educated elite. But rather than rejecting late colonial IE, Anand and Singh incorporate many of its nativized features into his creative dialectespecially morphological and syntactical features-while giving them a more distinctly Indian lexical texture. Their agenda, in the main, seems to have been to make IE more overtly 'culture-bound in the socio-cultural setting of India', though without effecting a radical transformation of English speech 
and idiom. In this process, Anand and Singh's English become not just 'more Indian' than its contemporary real-world counterpart, but more democratic as well, reflecting the language habits of all Indian, not just the educated elite.

They courageously have taken the step to handle the language of Britishers they incorporate many of their regional nativized features into their creative dialect-especially morphological and syntactical features-while giving them a more distinctly Indian lexical texture. His agenda, in the main, seems to have been to make IE more overtly 'culture-bound in the socio- cultural setting of India' (Kachru 1966:410).

\section{REFERENCES}

[1] Anand, Mulk Raj. Untouchable. 1935. Navi Mumbai: Penguin India.

[2] Ashcroft, Bill, Gareth Griffiths, and, Helen Tiffin. 2006. Eds. The Post-Colonial Studies Reader. London and New York: Taylor \& Francis.

[3] Bhabha, Homi K. 2012. The Location of Culture. New York: Routledge.

[4] Bose, Brinda. 2003. Amitav Ghosh: Critical Perspectives. Delhi: Pencraft International. Chaudhuri, Supriya. 2009. "Translating Loss: Place and Language in Amitav Ghosh and

[5] Salman Rushdie." Études anglaises 62, no. 3: 266-279.

[6] Ghosh, Amitav. 2000. The Hungry Tide. India: Penguin Books India. Ghosh, Amitav. 2008. Sea of Poppies: A Novel. New York: Picado. Ghosh, Amitav. 2010. The Shadow Lines. India: Penguin Books India.

[7] Kachru, Braj B. 1992. The Other Tongue: English across Cultures. Urbana and Chicago: University of Illinois Press.

[8] Kachru, Braj B. 1990. The Alchemy of English: The Spread, Functions, and Models of Non- Native Englishes. Urbana and Chicago: University of Illinois Press.

[9] Lefevere, André. 1999. "Composing the Other." In Post-Colonial Translation: Theory and Practice, 75-94. Edited by Susan Bassnett and Harish Trivedi. London: Routledge.

[10] Prasad, G. J. V. 1999. "Writing Translation." In Post-Colonial Translation: Theory and Practice, 41-56. Edited by Susan Bassnett and Harish Trivedi. London: Routledge.

[11] Simon, Sherry and Paul St-Pierre. 2001.Changing the Terms: Translating in the Postcolonial Era. Canada: University of Ottawa Press/Les Presses de l'Université d'Ottawa.

[12] Singh, Khushwant. 2005. Train to Pakistan. New Delhi: Thomson Press India.

[13] Mehrotra, A. K. 2003. An Illustrated History of Indian English Literature. New Delhi: Permanent Black.

Citation: Bhawna, Dr. Pashupati Jha. Translating Social Differences in Select IWE (Indian Writing in English): A Bilingual Perspective "International Journal on Studies in English Language and Literature (IJSELL), vol 7, no. 6, 2019, pp. 1-9. doi: http://dx.doi.org/10.20431/2347-3134.0706001.

Copyright: () 2019 Authors. This is an open-access article distributed under the terms of the Creative Commons Attribution License, which permits unrestricted use, distribution, and reproduction in any medium, provided the original author and source are credited. 